\title{
Polymer (Polydimethylsiloxane (pdms)) Microchip Plasma with Electrothermal Vaporization for the Determination of Metal Ions in Aqueous Solution
}

\author{
WonKyung Ryu, DongHoon Kim, H. B. Lim, and R. S. Houk* \\ Deparment of Chemistry, Dankook Lniversin-ASBT, Seoul 140-714, Korea. ${ }^{*}$ E-mail: plasmagldankook ackr \\ Department of Chemistry, Iowa State Lniversity-Ames Lab, Ames, IA 50011, LSA \\ Received November 22, 2006
}

\begin{abstract}
We previously reported a $27.12 \mathrm{MHz}$ inductively coupled plasma source at atmospheric pressure for atomic emission spectrometry based on polymer microchip plasma technology. For the PDMS polymer microchip plasma. molecular emission was observed. but no metallic detection was done. In this experiment. a lab-made electrothermal vaporizer (ETV) with tantalum coil was connected to the microchip plasma for aqueous sample introduction to detect metal ions. The electrode geometry of this microchip plasma was redesigned for better stability and easy monitoring of emission. The plasma was operated at an if power of $30-70 \mathrm{~W}$ using argon gas at $300 \mathrm{~mL} / \mathrm{min}$. Gas kinetic temperatures between $800-3200 \mathrm{~K}$ were obtained by measuring $\mathrm{OH}$ emission band. Limits of detection of about $20 \mathrm{ng} / \mathrm{mL}$. $96.1 \mathrm{ng} / \mathrm{mL}$. and $1.01 \mu \mathrm{g} / \mathrm{mL}$ were obtained for alkali metals. Zn. and $\mathrm{Pb}$. respectively, when $10 \mu \mathrm{L}$ samples in $0.1 \%$ nitric acid were injected into the ETV.
\end{abstract}

Key Words : Microchip plasma, Electrothermal vaporization. Atomic emission, Plasma spectroscopy

\section{Introduction}

Various microchip plasmas have been developed for analytical detection sources. These miniaturized sources are versatile and can be used for molecular and atomic emission as well as ionization source for mass spectrometry. The best well-known application for them currently is a GC detector ${ }^{1-4}$ There have been several papers on other microplasma sources based on different kinds of plasma generation tecluniques. ${ }^{5-9}$ Various materials and creative geometries have also been used for performance improvement and miniaturization. In general fused silica capillaries were used for micro plasma generation. and glass or quartz chips were designed for microchip plasmas. However those materials are difficult to be manufactured and vulnerable to be attacked by fluorine compound. We recently reported a PDMS polymer microchip if plasma for the detection of fluorinated carbons for the first time. ${ }^{10}$ This PDMS microchip can be manufactured easily. is inexpensive and is more tolerant to plasmas containing fluorocarbons than the silica microchip.

The electrothermal vaporizer (ETV). as a vaporization source. has proven to be a very useful teclunique for sample introduction in various atomic spectrometry techniques ${ }^{1 l-13}$ because of the higher transport efficiency of dry aerosols. the micro sampling capability. ${ }^{14.15}$ and the potential for direct solid analysis and minimal sample pre-treatment. ${ }^{16-18}$ All of the ETV sample introduction methods in micro plasma spectrometry were studied for the plasma formed in glass or quartz chip or tube. No report for atomic emission using ETV in polymer or plastic microchip plasma exists so far. For the PDMS microchip plasma. only gas samples. such as fluorinated carbons. were demonstrated in our previous work. ${ }^{16}$ In that report the background emission spectrum consists mainly of various molecular bands particularly $\mathrm{OH}$. $\mathrm{NH}$ and $\mathrm{NO}$ bands and $\mathrm{CF}_{4}$ gas at $0.1 \%$ in argon yields mainly $\mathrm{C} \_$emission bands. It would be interesting to observe atomic emission in the polymer microchip plasma. which generally requires higher energy than the molecular enission. For the PDMS microchip plasma as an atomization source, it will be useful to introduce aqueous sample to observe atomic or ionic emission.

In this work, a lab-made electrothermal vaporizer (ETV) with tantalum coil ${ }^{19}$ is connected to the PDMS polymer microchip plasma to observe atomic emission in aqueous sample. The electrode geometry is changed from top-bottom to side-ty'pe for better stability and easy monitoring of emission. Since the plasma is formed inside the PDMS polymer channel. it is interesting to estimate the gas temperature of the plasma as an atomization source. which can be estimated from the $\mathrm{OH}$ band emission. For analytical application the atomic emissions of several metals. such as $\mathrm{K} . \mathrm{Pb}$. etc. are observed. The analytical figures of merits are determined after optimizing the PDMS polymer microchipoptical emission șistem with ETV.

\section{Experimental}

The schematic diagram of the system used in this experiment is shown in Figure 1.

The if plasma formed in PDMS polymer to detect fluorinated carbons was described in the previous paper. ${ }^{10}$ The electrode geometry of that PDMS polymer microchip plasma was top-bottom type. of which two flat copper electrodes were inserted into the top and bottom slots of the channel. so the electrodes covered the plasma from the top. In this work. the electrode geometry is changed from top-bottom to sidetype (L-type) for better stability and easy monitoring of emission, as seen in Figure 2. The electrodes and the torch are molded using PDMS. The plasma torch channel is $2 \mathrm{~mm}$ in diameter and $50 \mathrm{~mm}$ in length. The top and bottom halves 


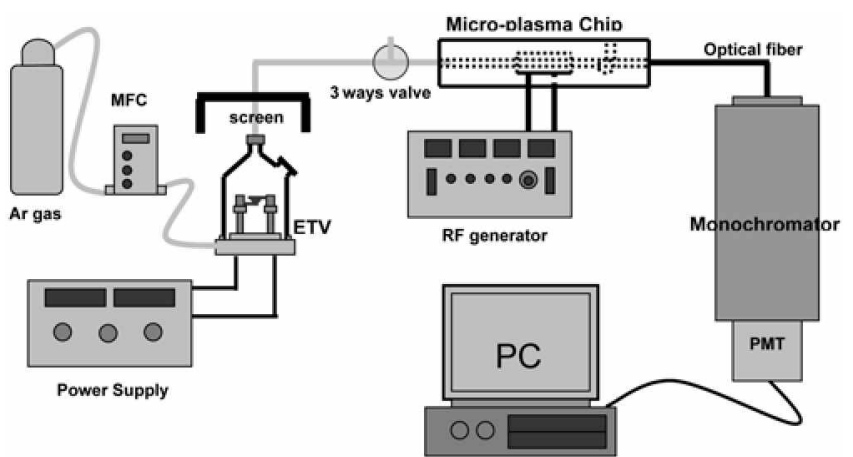

Figure 1. Schematic diagram of ETV-microchip plasma (ETVMCP) system.

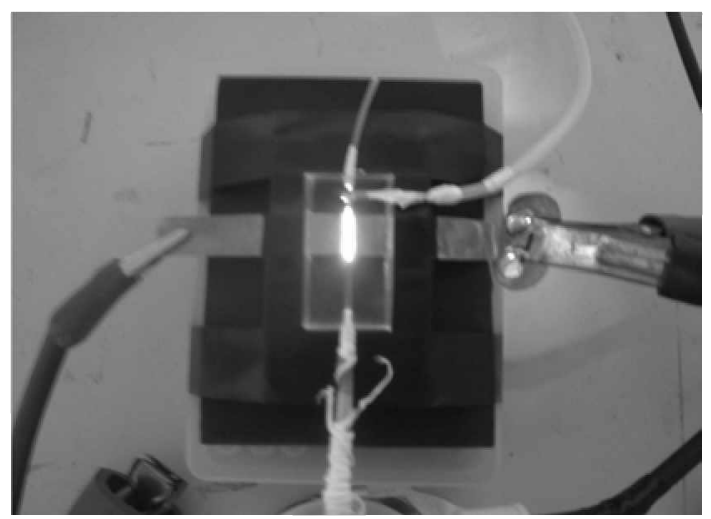

Figure 2. Picture of PDMS polymer microchip plasma with L-type electrode.

of the chip are sealed together by the plasma bonding teclunique in which the polymer surface is plasma-treated in the presence of oxygen. An optical fiber for light collection is inserted into the downstream end of the channel. Emission was observed axially using a $0.75 \mathrm{~m}$ focal length monocluromator (DongWoo Scientific Co. Seoul. Korea) with a grating of 2400 grooves $/ \mathrm{mm}$ and $80 \mu \mathrm{mm}$ slit widths and a photomultiplier tube (PMT. R950. Hamamatsu Co.). The spectrum was obtained using the software provided by the manufacturer. A purge gas of $300 \mathrm{~mL} / \mathrm{min}$ flow rate is added to cut off the tail plume of the plasma about $4.5 \mathrm{~mm}$ away from the copper electrodes in order to protect the optical fiber. Two flat copper plates ( $6 \mathrm{~mm}$ wide $\times 0.3 \mathrm{~mm}$ thick) are used for the L-type electrodes. so the plasma formed inside the channel can be seen easily from the top. The gap between the electrodes and channel is about $0.5 \mathrm{~mm}$. RF power $(27.12 \mathrm{MHz}$. RF generator and matching box. Model YSE-06F. Youngsin Engineering. Korea) is applied to the electrodes to generate the plasma. The plasma was operated at an if power of $30-70 \mathrm{~W}$ using argon gas at about $300 \mathrm{~mL} /$ min regulated by mass flow controllers (MFC. Model 580E series. Brooks. Japan).

Electrothermal vaporization system. For sample solution introduction. the same lab-made electrothermal vaporization (ETV) system reported previously was used ${ }^{15}$ in which the chamber was made of a Teflon base $(5 \mathrm{~cm} \times 5 \mathrm{~cm}$ $\times 2.5 \mathrm{~cm}$ ) and a conical Pỵrex glass housing $(5 \mathrm{~cm}$ in height).
The electrodes were made of two copper bars. Tantalum foil (Aldrich. USA). $0.025 \mathrm{~mm}$ in thickness and $0.2 \Omega$ in resistance $(30 \mathrm{~mm} \times 0.7 \mathrm{~mm})$ for filament was used to vaporize the sample. In routine operation process. a sample of $10-20$ $\mu \mathrm{L}$ was loaded onto the tantalum filament and vaporized by thermal energy at $200^{\circ} \mathrm{C}$. After the solvent droplets were vented out through the 3-way valve. the gas flew into the microchip torch. and then. the plasma was turned on for emission measurement. If the sample wasn't dried completely. the plasma can't be turned on. All experimental conditions were the same as the reported before. ${ }^{19}$

The typical electrothermal vaporization system was composed of three parts: a chamber with an argon gas inlet and a sample-injection port. filament and electrodes with a cooling system. and power supply to heat the plate. The chamber was made of a Teflon base and a Pyrex glass housing in a cone shape. The size of the base was $7 \mathrm{~cm} \times 7 \mathrm{~cm} \times 3 \mathrm{~cm}$ and the housing was $5.0 \mathrm{~cm}$ in base and $7 \mathrm{~cm}$ in height. The gas flow of argon inside the housing was in a spiral fonmation. making the housing cool and efficiently sweeping the vaporized sample into the plasma. The flow rate determined the gas flow rate of the plasma fomed in the torch. The electrodes were made of copper bars to give low resistance and high thermal conductivity for cooling. For the filament. a tantalum foil (Aldrich. USA). $0.025 \mathrm{~mm}$ in thickness and $0.2 \Omega$ in resistance $(30 \mathrm{~mm} \times 0.7 \mathrm{~mm})$ was used to vaporize the sample. The current was supplied to the filament by a power supply (HS-10100D. Max. 100A. HwaSung Electronics Corp. Seoul. Korea). The outlet of the chamber was connected to the inlet of the sample injector of the plasma torch through trgon tubing. In order to measure the temperature of ETV gas. a thenmocouple detector (AT-3-K. Max $1500{ }^{\circ} \mathrm{C}$. Hanyoung Corp.. Seoul, Korea) was used.

\section{Results and Discussion}

Plasma formation and ETV system. The plasma formed in a PDMS polymer microclip was stable for more than 8 hrs of operation. and the microchip could be used more than a month. The stability of the plasma strongly depended upon the operating conditions such as the gas flow rates for the plasma formation and cutting gas. the power. and the gap between electrodes. For example. if the flow rate of the cutting gas didn't match with optimum condition. the plasma couldn't be sustained. The plasma condition could be observed from the top because the electrodes were positioned at the side of the channel. so adjustment of the operating conditions can be easily done. If the power was increased to $>90 \mathrm{~W}$ a brighter plasma was observed. but the microchip changed from transparent to yellow. However. this effect didn't reduce the transmittance of the emission into the optical fiber because there was no PDMS between the plasma and the fiber tip. The cutting gas kept the optical fiber from etching.

Optimization of ETV-microchip plasma system. The temperature of the ETV was increased in two steps. First. the solvent. water. was evaporated. and then the dried salts were 

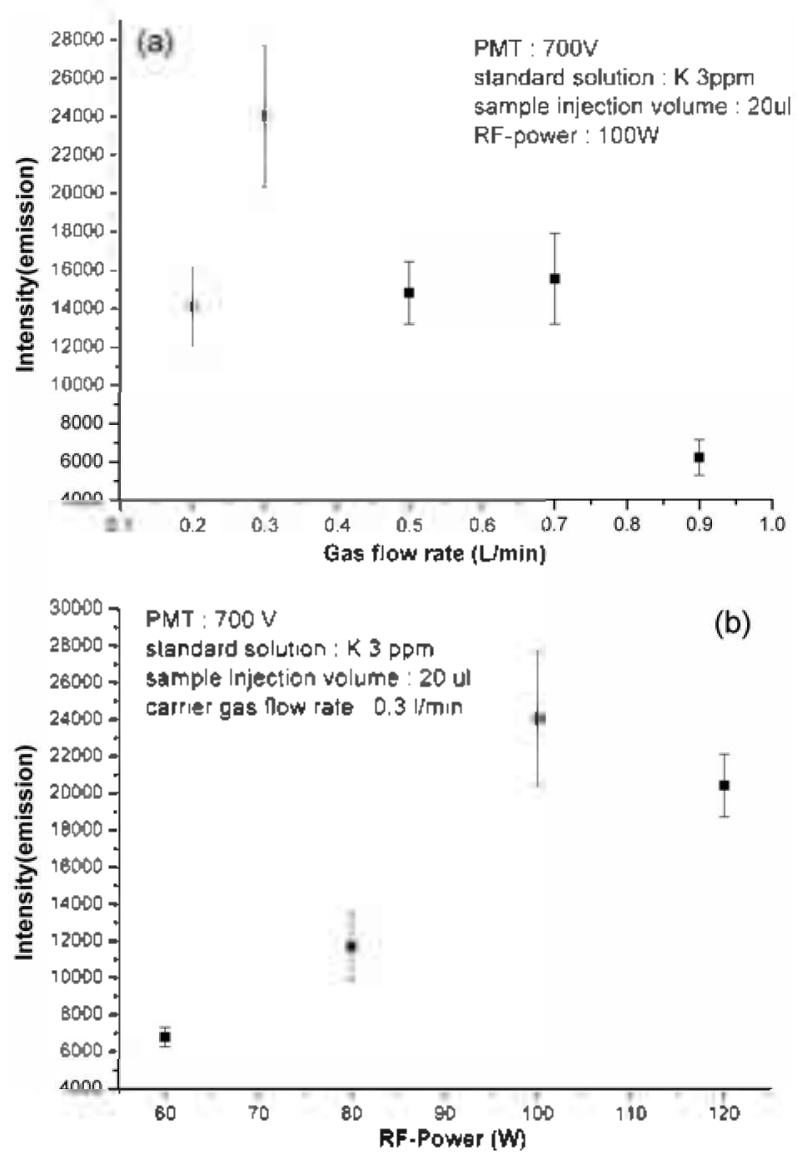

Figure 3. Effect of gas flow rate (a) and if power (b) on K I intensity in ETV-MCP system.

evaporated. A three-way tee was used to vent the evaporated solvent during the first step prior to introducing analyte particles into the plasma. as shown in Figure 1. Otherwise. the plasma couldn't be sustained. Using this technique only' dry particles were introduced into the plasma.

Gas flow rate and if power were adjusted for optimization when $3 \mu \mathrm{g} / \mathrm{mL}$ of $\mathrm{K}$ was injected. Figure 3(a) shows the signal change of $\mathrm{K}$ at $766.49 \mathrm{~nm}$ while gas flow rate is varied. The enror bars were calculated from data from three different days. Although it could be difficult to find the optimum flow rate maximum signal was obtained at flow rates between $300-400 \mathrm{~mL} / \mathrm{min}$. If the flow rate was over 1.0 $\mathrm{L} / \mathrm{min}$. ignition and sustaining the plasma became difficult. and if it was lower than $0.1 \mathrm{~L} / \mathrm{min}$. the PDMS microchip was damaged. In this experiment. the cutting gas should be used all the time. The rf power also affected signal intensity of $\mathrm{K}$. as shown in Figure 3 (b). At power less than $70 \mathrm{~W}$, the plasma was stable although the intensity was relatively low. As the power was increased the intensity was increased and maximized at $100 \mathrm{~W}$ : however the plasma became unstable. If the power was over $120 \mathrm{~W}$, the PDMS microchip degraded turning yellow. Clearly. the plasma stability and sensitivity were very dependent on gas flow rate and $\mathrm{rf}$ power.

Plasma temperature. Rotational temperature was measured from the diatomic spectrum of $\mathrm{OH}$. The molecular emission intensity was strong enough to be measured even

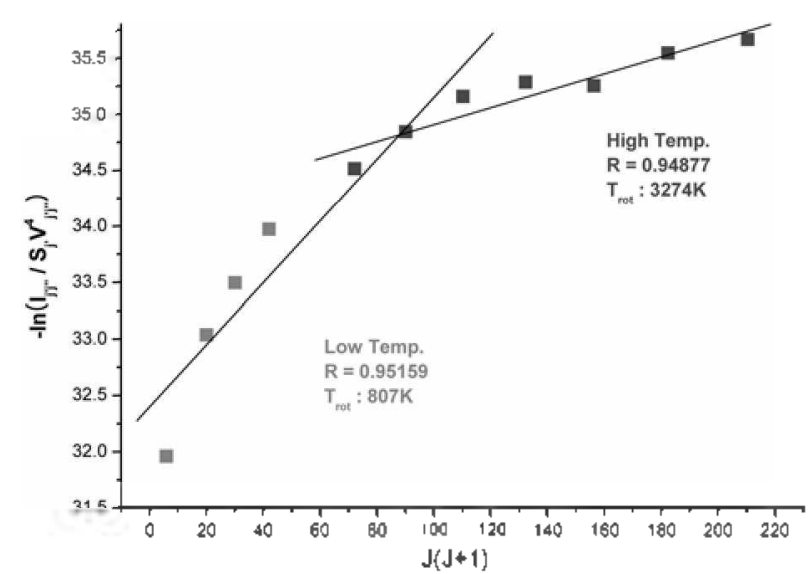

Figure 4. Plot for gas kinetic temperature measurement using $\mathrm{OH}$ spectrum.

though no water was introduced. The entrainment of air through the porous PDMS was a likely reason for this. The temperature was calculated using a previously described method. ${ }^{31}$ Measurements were made on lines spanning $Q_{1}(2)$ to $\mathrm{Q}_{1}(14)$ in the $3075-3115 \AA$ region for the $\mathrm{OH}$ radical. Several lines were omitted from the calculation because of unresolved bands and spectral interferences. Plotting - ln

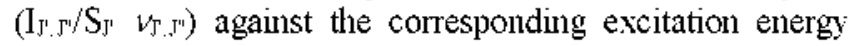
gave two straight lines with slope equal to $1 / \mathrm{kT}$. A representative plot is illustrated in Figure 4, showing two rotational temperatures. 'low' and 'high'. The low temperature was obtained using the lines of J' value from 2 to 10 . and the high temperature was obtained using J' from 8 to 14 . This kind of a non-linear rotational distribution was already reported and discussed by several researchers ${ }^{30}$ and was characterized as the sum of two separate Boltzmann distributions. and was characterized as the sum of two separate Boltzmann distributions.

As shown in Figure 4, the gas kinetic temperatures were found to be $810 \mathrm{~K}$ and $3300 \mathrm{~K}$ for the low and the high temperature, respectively. Compared to the low pressure plasma operated at $\sim 1$ torr. ${ }^{2 \mathrm{il}}$ the low temperature was almost

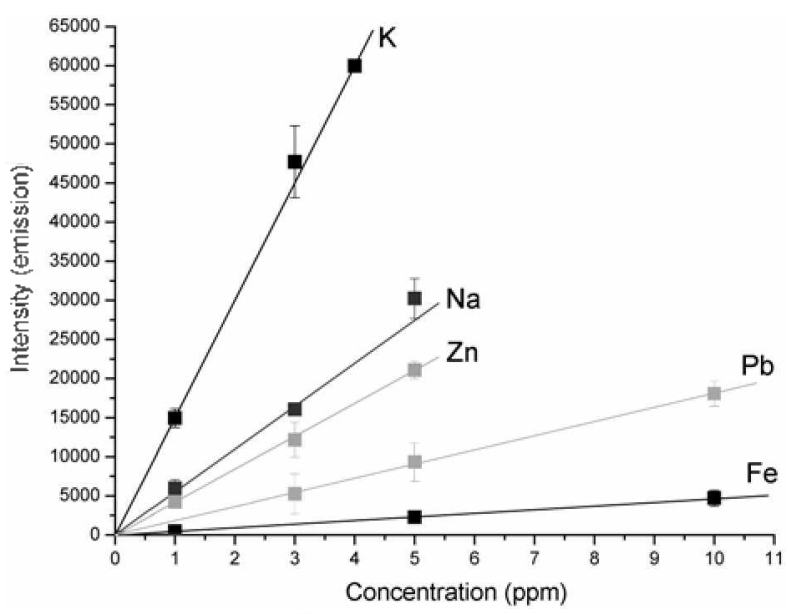

Figure 5. Normalized calibration curves including error bars for $\mathrm{K}$, $\mathrm{Na}, \mathrm{Pb}, \mathrm{Zn}$, and $\mathrm{Fe}$ 

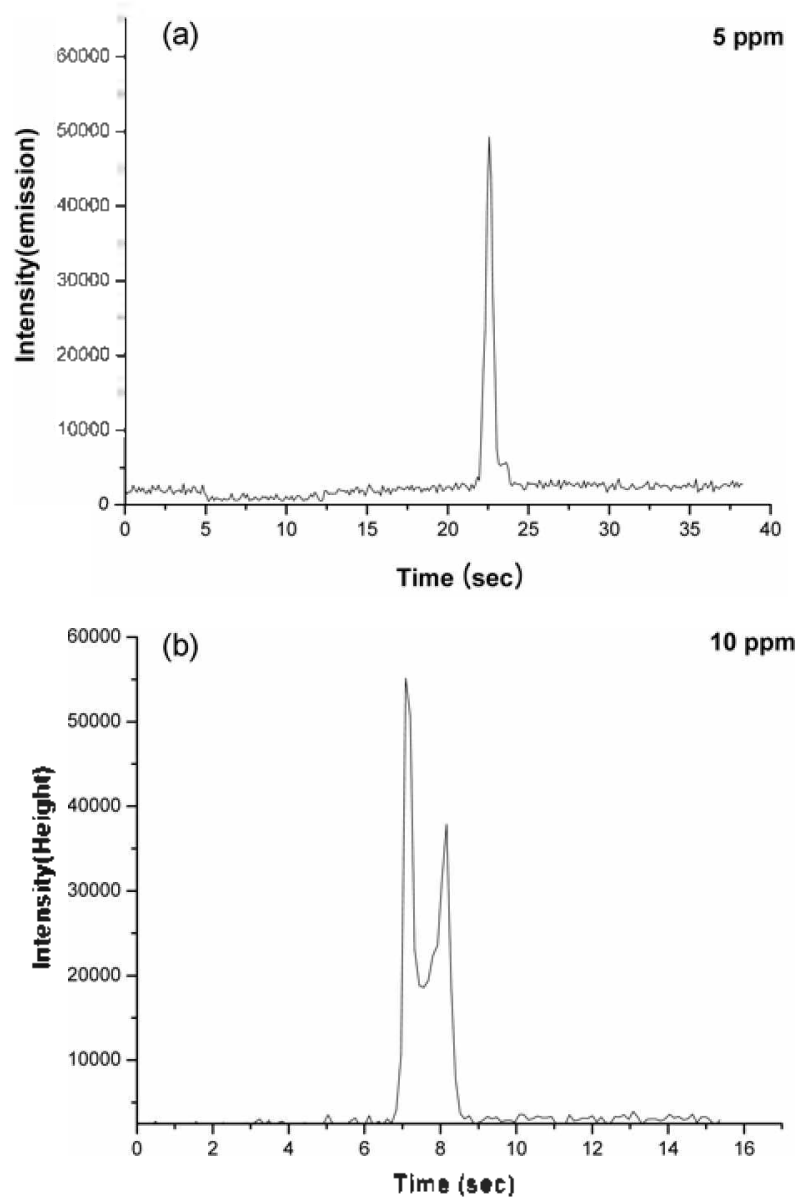

Figure 6. Time resolved spectra of $5 / / \mathrm{g} / \mathrm{mL} \mathrm{K} \mathrm{(a)} \mathrm{and} 10 / \mathrm{g} / \mathrm{mL}$ $\mathrm{Pb}(\mathrm{b})$ in ETV-MCP system.

the same, and the high temperature was increased. Both temperatures were lower than the results reported for atmospheric pressure plasmas.

Analytical figures of merit. Limits of detection for $\mathrm{K} . \mathrm{Pb}$. $\mathrm{Zn}$. Fe. and $\mathrm{Na}$ were estimated from the calibration curves. The calibration curves $\left(R^{2}>0.991\right)$ were obtained from the atomic emission lines of K I. $766.49 \mathrm{~nm}$. Pb I. $405.78 \mathrm{~mm}$. Zn I. $330.26 \mathrm{~mm}$. Fe I. $357.01 \mathrm{~nm}$. and Na I. $588.89 \mathrm{~mm}$. Normalized calibration curves. including error bars obtained by four measurements. are shown in Figure 5 . Time resolved spectra of $5 \mu \mathrm{g} / \mathrm{mL} \mathrm{K}$ and $10 \mu \mathrm{g} / \mathrm{mL} \mathrm{Pb}$ are shown in Figure 6(a) and (b), respectively. Compared to $K$, the spectrum of $\mathrm{Pb}$ had two peaks due to fractionation caused by different anions of the salt. Therefore. integrated peak area was used for the calibration. No ionic emission lines were used for this study due to extremely low emission intensity or no observation. Measurement was repeated four times. Limits of detection of $7 \mathrm{ng} / \mathrm{mL} .23 \mathrm{ng} / \mathrm{mL}$. $49 \mathrm{ng} / \mathrm{mL} .143 \mathrm{ng} / \mathrm{mL}$. and 597 $\mathrm{ng} / \mathrm{mL}$ with relative standard deviation of $<5.6 \%$ were obtained for $\mathrm{K}, \mathrm{Na}, \mathrm{Zn}, \mathrm{Pb}$. and $\mathrm{Fe}$, respectively, when $10 \mu \mathrm{L}$ samples in $0.1 \%$ nitric acid were injected into the ETV. Based on these results. hybridization of ETV with a PDMS microchip plasma with low if power made it possible to determine metals in aqueous samples by the observation of atomic lines

Acknowledgement. This work was supported by Korea Research Foundation Grant funded by Korea Govemment (MOEHRD. Basic Research Promotion Fund) (KRF-2005015-C00294).

\section{References}

1. Bessoth. F. G:- Naji. O. P.: Eijkel, P. J. C. T.: Manz, A. J. Anal. At. Spectront 2002. 17.794.

2. Eijkel. T. C. T.: Stoeri. H.: Manz. A. Andl. Chent 1999. 71. 2600.

3. Eijkel. T. C. T.: Stoeri. H.: Matzz. A. J. Anal. At Spectront 2000. 15.297.

4. Kunze. K.: Miclea. M.: Fanzhe. J.: Niemax. K. Spectrochim. Acta $B 2003,58.1435$.

5. Engel. U.; Bilgic, A. M.; Haase. O.; Voges. E.; Broekaert, J. A. C. Anal. Chem. 2000, 72. 193.

6. Minayeva. O. B.: Hopwond. J. A. J. Anal At. Spectron. 2002.17. 1103.

7. Franzke. T.: Kunze. K.: Miclea. M: Niemax. K. J. Anal. At. Spectrom 2003. 18,802

8. Guchardi. R.: Hauser, P. C. J. Anal. At. Spectrom. 2003, 18. 1056.

9. Karanassios, V. Spectrochimica Acta Part B 2004, $59,909$.

10. Lim. H. B.: Kim. D. H.: Jung. T. Y.: Houk. R. S.: Kim. Y. S. Anal. Chint deta 2005.545. 119

11. Kantor. T.: Maestre. S.: de Loos-Vollebregt. M. T. C. Spectrochintica Acta Part B 2005. 60(9:10). 1323.

12. Chen. S.; Lu. D.; Hu, Z.: Wu. B. Spectrochinica Acta Pat B 2005. $60(4), 537$

13. Saint'Pierre. T. D.: de Andrade Maranthầ. T.: Frescura. V. L. A.: Curtius. A. T. Spectrochintica Acta Port B 2005. 60(5). 605.

14. Kim. S.: Lim. J.: Lee. W.: Kim. Y.: Nam. S.: Lee. Y. Microchenical J. 2004, 78(2). 127 .

15. Lia. L.: Hu, B.; Xia, L.: Jiang. Z. Talanta 2006. $70(2), 468$.

16. Sturgeon. R. E.: Lam. J. W. J. Anal .At Spectrom. 1999. 14. 785.

17. Resano. M.: Verstraete. M.: Vanhaecke. F.: Moens. L. J. Anal. At. Spectront 2001. 16. 1018.

18. Karanassios. V.: Grisko. V.: Reynolds. G. G. J. Anal At Spectront 1999. 14,565

19. Jung. T. Y.: Kim, Y. S.: Lim. H. B. Analyical Sciences 2005, 21. 569

20. Sung. Y. I. Lim. H. B. J. Anal At. Spectrom. 2003. 18.897. 